\title{
Age, player position and 2 min suspensions were associated with match injuries during the 2017 Men's Handball World Championship (France)
}

\author{
Montassar Tabben, ${ }_{1}^{1}$ Philippe Landreau, ${ }^{1}$ Karim Chamari, ${ }^{1}$ Gerard Juin, ${ }^{2}$ Hosny Ahmed, ${ }^{3}$ \\ Abdulaziz Farooq, ${ }^{1}$ Roald Bahr, ${ }^{1,4}$ Nebojsa Popovic ${ }^{1}$
}

${ }^{1}$ Aspetar Orthopedic and Sports Medicine Hospital, Doha, Qatar ${ }^{2}$ French Handball Federation, Paris, France

${ }^{3}$ International Handball Federation, Basel, Switzerland ${ }^{4}$ Department of Sports Medicine Oslo Sports Trauma Research Center, Norwegian School of Sport Sciences, Oslo, Norway

\section{Correspondence to} Dr Montassar Tabben, The Aspetar Sports Injury and IIIness Prevention Program (ASPREV) Department, Doha 29222, Qatar;

Montassar.Tabben@aspetar.com

Accepted 27 August 2018

Published Online First

15 September 2018
Check for updates

(C) Author(s) (or their employer(s)) 2019. No commercial re-use. See rights and permissions. Published by BMJ.

To cite: Tabben $\mathrm{M}$ Landreau P, Chamari K et al. Br J Sports Med 2019:53:436-441.

\section{ABSTRACT}

Aim To study the association between player characteristics, technical components of the game and the risk of match injuries during the 2017 Men's Handball World Championship.

Methods Team physicians of the participating teams $(n=24)$ were requested to provide injury report forms throughout the Men's Handball World Championship (France, January 2017). The individual time played, age, number of international matches played and all technical and penalty variables for each player were extracted from the official International Handball Federation (IHF) online database and used as risk factors in a general logistic linear model analysis.

Results Of 387 players, 49 sustained one or more injuries (93 injuries in total). The total incidence of match injuries was 82.1 injuries per 1000 hours $(95 \% \mathrm{Cl} 66.2$ to 100.5), non-time-loss injury incidence was 40.6 injuries per 1000 hours $(95 \% \mathrm{Cl} 29.3$ to 54.9$)$, while timeloss injury incidence was 30.9 injuries per 1000 hours (95\% Cl 21.5 to 42.9$)$. Multivariate analysis showed that age (OR 1.1, 95\% Cl 1.02 to $1.18, \mathrm{p}=0.011)$, player position (backs: OR 6.79, 95\% Cl 2.25 to 20.54, $p=0.001$; goalkeepers: OR 5.03, $95 \% \mathrm{Cl} 1.15$ to 21.94 , $p=0.031$ ) and 2 min suspensions (1-2 times: OR 2.77, $95 \% \mathrm{Cl} 1.27$ to $6.04, p=0.011 ; 3$ or more times: OR $2.66,95 \% \mathrm{Cl} 1.18$ to $6.38, p=0.029$ ) were significant risk factors for getting injured during competition matches.

Conclusion Age, player position (backs, goalkeepers) and 2 min suspensions were associated with match injury. Stricter rule enforcement should be considered to prevent match injuries in elite handball.

\section{INTRODUCTION}

Handball is a modern Olympic sport played by two competing teams of seven players on an indoor court over two halves of $30 \mathrm{~min}$. Matches are characterised by repeated bouts of high-intensity activity with frequent contacts and collisions between players $^{1}{ }^{2}$ resulting in handball being one of the Olympic team sports with the highest risk of injury over the last four summer Olympic games. $^{3-6}$ For instance, during the 2012 Olympic games, handball had the fourth highest injury score (22\%) after taekwondo, football and BMX (39\%, $35 \%$ and $31 \%$ of registered athletes were injured, respectively). ${ }^{3}$

Descriptive analysis of the injury pattern alone is insufficient to develop preventive measures.? Studying risk factors of specific-sport injuries is

\section{What are the findings?}

- Older players were at greater risk of match injury.

- Players sanctioned with 2 min suspensions were approximately three times (one to two times: OR 2.77 and three or more times: OR 2.66) more likely to sustain an injury compared with players remaining suspension-free.

- Back players were at approximately seven times greater risk of injury compared with wing players.

How might it impact on clinical practice in the future?

- Handball coaches and medical staff should consider focusing on ways/techniques to reduce injury risk by recommending their players to decrease 2 min suspensions.

- The IHF has already advised referees to heavily sanction fouls against attacks from the wing, and it seems reasonable to consider what can be done to protect the back positions in a similar way.

necessary to provide a better understanding of the injury mechanism ${ }^{8}$ and therefore develop effective injury-prevention strategies. ${ }^{1}$ Despite some studies have identified that previous injury ${ }^{19}$ and lack of proprioception $^{9}$ are risk factors for handball-related injuries, prospective studies aiming at investigating the risk factors of handball injuries are limited. According to Hopkins et al, ${ }^{10}$ player characteristics and behaviours (eg, age, skill, playing position and game strategies) are the most relevant risk factors.

In recent years, match analysis has become an important tool in team sports to gain a deeper insight into the technical, tactical and physiological demands of the game. ${ }^{1112}$ This methodological approach is used to quantify the mode and frequency of discrete activities performed during the match. ${ }^{13}$ Consequently, using the match analysis outcomes in order to associate player characteristics and behaviours with injuries, could enable better understanding of the factors associated with match injuries in handball and thereby guide prevention strategies at the elite level. ${ }^{1415}$ Thus, the aims of this investigation were to describe the pattern of injuries 
during matches of the 2017 Men's Handball World Championship (the Tournament) and to study the association between player characteristics and the technical components of the game with the risk of match injuries during the tournament.

\section{METHODS}

The methodology and procedures of this study were established based on the IOC injury and illness surveillance protocol, ${ }^{3616} 17$ using methodology adapted for handball as described in detail by Bere et al. ${ }^{18}$

\section{Injury data collection}

Team medical staff agreed to participate in the study during the first official team medical meeting of the event, held in Paris 2 days prior to the first match.

Team physicians of the participating teams $(n=24)$ and chief physicians of each of the tournament sites were both requested to provide separate injury report forms for each match of the Men's Handball World Championship (France, 11-29 January 2017). They were asked to complete and submit, for each single match, a standardised one-page report form with predetermined categories, definitions and codes, ${ }^{18}$ regardless of whether or not any injury had occurred. The report form with definitions and categories was available in six languages (English, Arabic, French, Spanish, German and Russian), so there should be no language barrier to completion of the forms by team medical staff.

The team injury report form was submitted immediately after the match by each team's medical staff to the chief physician of the site at which the match was played (there were five competition sites in total).

The chief physician was required to submit both the team injury reports and the local organising medical committee injury report forms (by 11:00 hours the following day) to the chief medical officer of the tournament. The team injury report forms could therefore be crosschecked with the injury reports from the local medical teams.

\section{Definition of injury}

An injury was defined as 'any musculoskeletal complaint newly incurred due to competition and/or training during the tournament that received medical attention regardless of the consequences with respect to absence from competition or training'. This injury definition includes five aspects: (1) all injuries that received medical attention (those that resulted in time-loss or reduced performance), (2) newly incurred (exclusion of pre-existing and not fully rehabilitated injuries), (3) injuries occurring in competition or training, (4) injuries occurring during the period of the tournament and (5) exclusion of illnesses and diseases.

For each injury, the reporting form included information about injury location, type, cause (ie, contact between players, contact with objects, non-contact trauma, overuse injuries, violation of rules and other), whether or not the player returned to the game just after the injury as well as injury severity (ie, 1-2 days, 3 days -4 weeks or $>4$ weeks) reported as the time to return to play. The team's medical staff was required to update any missing date of return to play by informing the chief physician of the site about the date of return to play of the injured player. If players did not return before the end of the competition, the staff were asked to provide an estimated date.

As the aim of the current article was to study the association between performance characteristics of players and their risk of injury during matches, training injuries were excluded and only match injuries were presented and used in the analysis.

\section{Exposure and technical data}

The age, time spent on court for each match during the present tournament and the total number of international matches played in the career (before the start of the tournament) of each

Table 1 Description of player characteristics, technical and penalties variables used in the analysis

\begin{tabular}{|c|c|}
\hline \multicolumn{2}{|l|}{ Player characteristics } \\
\hline Time played & The cumulative individual time played by each player during the competition. \\
\hline Age & The chronological age of each player. \\
\hline International matches played & The number of international matches played by each player in his career. \\
\hline Player position & According to the IHF database each player has a common position in the team formation: wing back, line and goalkeeper. \\
\hline \multicolumn{2}{|l|}{ Shot variables } \\
\hline Shots attempted & The overall count of all the shots attempted. \\
\hline $6 \mathrm{~m}$ shots & The total number of attempted throws by each player from the $6 \mathrm{~m}$ line. \\
\hline $7 \mathrm{~m}$ shots & The total number of shots by each player from the $7 \mathrm{~m}$ line (penalty kicks). \\
\hline $9 \mathrm{~m}$ shots & The total count of all attempted throws by each player from the $9 \mathrm{~m}$ line. \\
\hline Wing shots & All the attempted shots from the wing positions. \\
\hline Breakthrough shots & All shots attempted by an attacking player after making a breakthrough action (individual attempt to penetrate the defence line). \\
\hline Fast-break shots & $\begin{array}{l}\text { The total number of shots coming after a counter attack strategy (team attempts to move the ball up court and into scoring position as } \\
\text { quickly as possible). }\end{array}$ \\
\hline \multicolumn{2}{|l|}{ Offensive variables } \\
\hline Assists & The number of assists to prepare a shot for a partner (last pass before a partner is in position to shoot and actually makes a shot attempt). \\
\hline Turnovers & The number of action that a player performs in order to lead a counter attack. \\
\hline \multicolumn{2}{|l|}{ Defensive variables } \\
\hline Blocked shots & The number of actions which succeeded effectively to block opponent's shot. \\
\hline Steals & The number of steals that a player performs in order to get the ball back from the opponent. \\
\hline \multicolumn{2}{|l|}{ Penalties variables } \\
\hline 2 min suspensions & $\begin{array}{l}\text { The cumulative number of } 2 \text { min suspensions recorded by each player during the competition (one player is only permitted a maximum of two } \\
2 \text { min suspensions; at the third time, they will be shown the red card and leave the game). }\end{array}$ \\
\hline Yellow cards & The total number of yellow cards of each player during the competition (a player can get only one yellow card warning by match). \\
\hline Red cards & The count of red cards received by each player during the competition (a red card results in an exclusion from the game). \\
\hline
\end{tabular}


player were extracted from the official IHF online database. ${ }^{19}$ In addition, player position, the number of shots and the offensive, defensive and penalties variables (ie, 2 min suspensions, red and yellow cards) during the present tournament were extracted from the same website (table 1$).{ }^{19}$

The data were extracted to an Excel file where each player was characterised by each of the variables presented in table 1 . The primary outcome for the risk factor analysis was injured (yes or no). Data from matches for which there was no team medical staff injury report form were excluded from the extracted database.

\section{Data management and statistical analysis}

The data were analysed using SPSS software (IBM-SPSS statistics, V.23, Chicago, Illinois, USA) and analysed for normality using the Shapiro-Wilk test. Player characteristics and technical variables are presented as mean values $( \pm S D)$ and we used analysis of variance to compare these variables according to player position.

The number of 2 min suspensions was not normally distributed. Therefore, as per the distribution of the data, this variable was categorised into three groups: (i) no suspension, (ii) one to two suspensions and (iii) three or more suspensions. The red and yellow cards variable was grouped into two categories (yes or no).

A general logistic linear model was used to analyse the association between the potential risk factor variables and injury outcome. First, the relationship between each of the candidate risk factor variables and injuries was analysed in a univariate model. Variables with a $\mathrm{p}$ value of $<0.2$ in the univariate model were thereafter included in a multiple regression model. The potential predictive variables were also checked for multicollinearity and the variable with the highest association with injuries was included in the multiple regression analysis. Regression coefficients are presented as ORs with 95\% CIs and the model was adjusted for individual exposure. $\mathrm{P}$ values $<0.05$ were considered as statistically significant.

\section{RESULTS}

\section{Injury patterns}

There were 83 matches in the tournament. We received 156 of 166 potential daily report forms, corresponding to a total response rate of $94 \%$. In total, 93 injuries were reported. Of the 387 accredited players included in this study, 49 players sustained one or more injuries, meaning that $12.6 \%$ of the players suffered at least one injury during the tournament.

The total effective playing time of the players was 1133 hours. A significant difference in exposure was found between non-injured ( $\mathrm{n}=338$; mean: $2.9 \pm 1.6$ hours $)$ and injured $(n=49$; mean $=3.5 \pm 1.6$ hours $)$ players $(p=0.01$; mean difference: 0.6 ; 95\% CI 0.1 to 1.1 ).

Out of the total injuries, 42 were non-time-loss injuries (45.2\%), while there were 35 time-loss injuries (37.6\%). In 16 cases $(17.2 \%)$, information on injury severity was missing.

The total incidence of match injuries was 82.1 per 1000 hours (95\% CI 66.2 to 100.5$)$. The incidence of non-time-loss injuries was 40.6 per 1000 hours (95\% CI 29.3 to 54.9 ), while that of time-loss injuries was 30.9 injuries per 1000 hours (95\% CI 21.5 to 42.9 ).

Of the 35 time-loss injuries, 68.6\% $(\mathrm{n}=24)$ were mild $(1-2$ days loss), and $22.9 \%(\mathrm{n}=8)$ moderate (3 days to 4 weeks loss). Three severe injuries $(8.5 \%$; two knee injuries and one ankle injury) were reported (leading to an expected absence of $>4$ weeks).

The body parts most commonly injured were the ankle (19.3\%), head/face (17.3\%), knee (15.1\%) and thigh $(12.9 \%)$ (table 2). The most common injury types were contusions

Table 2 Number of injuries $(n=92)$ related to body part injured and injury severity, expressed as the estimated time of absence from full participation in training and match play

\begin{tabular}{|c|c|c|c|c|c|c|}
\hline Body part injured & 0 days & 1-2 days & 3 days -4 weeks & $>4$ weeks & NA & Total $(\%)$ \\
\hline Face & 10 & 4 & - & - & - & $14(15.1)$ \\
\hline Shoulder/clavicle & - & 1 & - & - & - & $1(1.1)$ \\
\hline Forearm & - & - & - & - & 1 & $1(1.1)$ \\
\hline Elbow & 2 & - & - & - & 1 & $3(3.2)$ \\
\hline Wrist & - & - & - & - & 1 & $1(1.1)$ \\
\hline Achilles tendon & - & 1 & 1 & - & - & $2(2.2)$ \\
\hline Head & - & 1 & 1 & - & - & $2(2.2)$ \\
\hline Hip & - & 1 & - & - & - & $1(1.1)$ \\
\hline Groin & - & 2 & 1 & - & - & $3(3.2)$ \\
\hline Thigh & 7 & 4 & - & - & 1 & $12(12.9)$ \\
\hline Knee & 6 & 3 & 1 & 2 & 2 & $14(15.1)$ \\
\hline Lumbar spine/lower back & 4 & 1 & - & - & 1 & $6(6.5)$ \\
\hline Abdomen & - & - & 1 & - & - & $1(1.1)$ \\
\hline Pelvis/sacrum/buttock & - & - & - & - & 1 & $1(1.1)$ \\
\hline Total (\%) & $42(45.2)$ & $24(25.8)$ & $8(8.6)$ & $3(3.2)$ & $16(17.2)$ & $93(100)$ \\
\hline
\end{tabular}

There were no injuries reported to the thoracic/upper back, neck/cervical spine, upper arm and hand.

NA, not available. 
Original article

Table 3 Comparison of the player characteristics and technical variables according to positions

\begin{tabular}{|c|c|c|c|c|}
\hline & \multicolumn{4}{|c|}{ Player position } \\
\hline & Back & Wing & Line & Goalkeeper \\
\hline Incidence rate (injuries/1000 hours) & 132.7 & 19.9 & 76.4 & 65.1 \\
\hline Time played (min) & $163.6 \pm 88.7$ & $203.6 \pm 105.4$ & $175.9 \pm 92.4$ & $167.5 \pm 100.5$ \\
\hline Age (years) & $26.1 \pm 4.3$ & $26.8 \pm 4.1$ & $27.4 \pm 4.6$ & $29.1 \pm 4.7$ \\
\hline International matches played & $62.1 \pm 61.8$ & $69 \pm 63.8$ & $72.8 \pm 68.3$ & $79 \pm 77.5$ \\
\hline Shots attempted (n) & $25.7 \pm 19.0^{*}$ & $22.9 \pm 15.9 \dagger$ & $13.9 \pm 11.6$ & $1.7 \pm 5$ \\
\hline $6 \mathrm{~m}$ shots $(n)$ & $6.5 \pm 5.7^{*}$ & $3 \pm 3.2$ & $10.5 \pm 9.8 \ddagger$ & $0.5 \pm 3.2$ \\
\hline $7 m$ shots $(n)$ & $1.6 \pm 4.1$ & $3.3 \pm 5.8$ & $0.1 \pm 0.5$ & - \\
\hline $9 m$ shots $(n)$ & $12.6 \pm 11.1 \S$ & $1.9 \pm 5.8$ & $0.6 \pm 1.8$ & $0.2 \pm 0.4$ \\
\hline Wing shots $(n)$ & $0.7 \pm 1.9$ & $9 \pm 6.99$ & $0.2 \pm 0.7$ & $0.1 \pm 1.1$ \\
\hline Breakthrough shots (n) & $2.0 \pm 2.4 \S$ & $0.4 \pm 1$ & $0.2 \pm 0.5$ & $0.1 \pm 0.1$ \\
\hline Fast-break shots (n) & $2.3 \pm 2.5$ & $5.3 \pm 4.59$ & $2.2 \pm 2.9$ & $0.9 \pm 1.5$ \\
\hline Assists (n) & $10 \pm 8.9 \S$ & $3.1 \pm 2.6$ & $3.7 \pm 3$ & $1.3 \pm 1.7$ \\
\hline Turnovers (n) & $6.6 \pm 5.1 \S$ & $2.8 \pm 3.0$ & $3.4 \pm 2.7$ & $0.7 \pm 2.5$ \\
\hline Blocked shots (n) & $1.1 \pm 1.9$ & $0.3 \pm 0.7$ & $2.0 \pm 2.2 \ddagger$ & $0.2 \pm 1.0$ \\
\hline Steals (n) & $1.6 \pm 2.3$ & $1.7 \pm 1.7$ & $1.3 \pm 1.5$ & $0.6 \pm 0.9$ \\
\hline
\end{tabular}

Results are presented as number of action \pm SD.

Goalkeepers were excluded from the analysis because only shots, defensive and offensive variables have been compared.

*Significant difference between back and wing $(p<0.05)$.

tSignificant difference between wing and line.

‡Significant difference between line and wing, as well as between line and back.

§Significant difference between back and wing, as well as between back and line.

ISSignificant difference between wing and back, as well as between wing and line.

$(46.2 \%, \mathrm{n}=43)$, followed by sprains $(30 \%, \mathrm{n}=26)$ and strains $(10.1 \%, \mathrm{n}=10)$.

In total, $45.3 \%(n=42)$ of all injuries resulted from contact between players, $11.8 \%(n=11)$ from contact with objects, $10.8 \%(\mathrm{n}=10)$ were as a result of non-contact trauma (sudden onset), $26.9 \%(\mathrm{n}=25)$ were overuse injuries (gradual onset) and $3.2 \%(\mathrm{n}=3)$ from other causes (ie, violation of rules and other).

\section{Game analysis and penalties}

As shown in table 3, back and wing players made more shot attempts than line players, while $6 \mathrm{~m}$ shots and fast-break shots were more often taken by line players. Back players led in $9 \mathrm{~m}$ shots, breakthrough shots, assists and turnovers.

The distribution of referee sanctions, $2 \mathrm{~min}$ suspensions and red cards, is presented in table 4 .

\section{Risk factor analysis}

There was no significant difference between injured and non-injured players regarding the number of total shots attempted ( $6 \mathrm{~m}$ shots, $9 \mathrm{~m}$ shots, $7 \mathrm{~m}$ shots, fast-break shots, breakthroughs,

Table 4 Penalty variables among injured and non-injured players

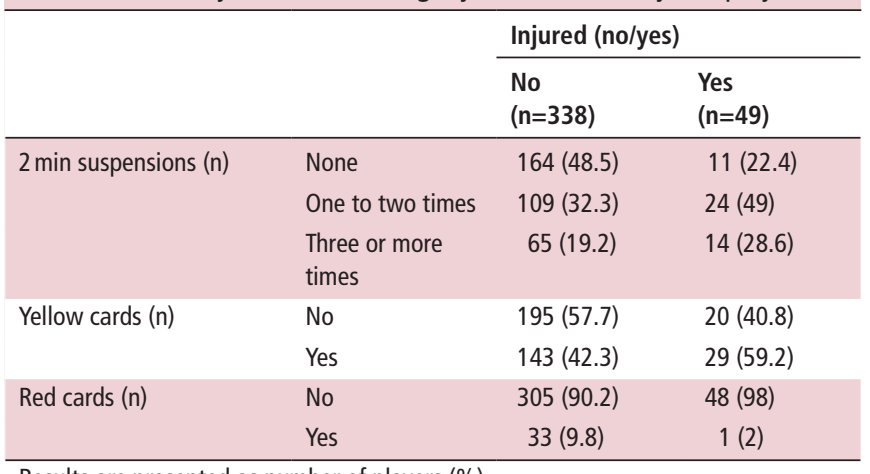

Results are presented as number of players (\%). turnovers, steals, blocked shots) or the rate of 2 min suspensions (number of suspensions per minute).

After univariate analyses examining the relationship between player characteristics and game analysis variables with injury risk (table 5), six candidate variables were included in a multiple logistic regression model (age, player position, wing shots, number of assists, number of 2 min suspensions and red cards). After a manual backward stepwise regression analysis, three variables (age, player position and 2 min suspensions) were retained in the final model and were independently associated with injuries (table 6).

\section{DISCUSSION}

No previous studies have tested the association between player characteristics, the technical components of the game and the risk of match injuries in high-level handball competition. Therefore, this study contributes to the handball injury literature as senior male handball competition injury risk factors are largely unknown. Based on the analyses of this study, age, player position and $2 \mathrm{~min}$ suspensions were associated with injury during the 2017 Men's World Handball Championship.

\section{Age}

Despite the fact that greater age has been identified by a number of investigators as an independent risk factor for several types of injury in many sports, ${ }^{20-26}$ no previous studies have investigated this finding in handball. Our findings demonstrate that older players were at higher risk of getting injured during competition compared with their younger counterparts. In this context, Moller $e t a l^{1}$ have reported that, for male senior, under-18 and under-16 players, the estimated match injury incidence was 23.5 (95\% CI 17.8 to 30.4 ), 17.2 (95\% CI 9.3 to 28.8 ) and 11.1 per 1000 match hours $(95 \%$ CI 7.0 to 16.6$)$, respectively. Unfortunately, the latter results cannot be directly compared with our findings, as in the present study there was a mix of players with 
Table 5 Univariate analysis adjusted by exposure (played time)

\begin{tabular}{|c|c|c|c|c|}
\hline & & \multicolumn{3}{|c|}{ Multiple regression } \\
\hline & & OR & $95 \% \mathrm{Cl}$ & $P$ values \\
\hline \multicolumn{2}{|l|}{ Age (years) } & 1.07 & 0.99 to 1.14 & 0.07 \\
\hline \multicolumn{2}{|c|}{ Number of international matches played } & 1.00 & 0.99 to 1.01 & 0.27 \\
\hline \multirow[t]{4}{*}{ Position* } & Wing & 1 & & \\
\hline & Line & 3.06 & 0.85 to 11.03 & 0.09 \\
\hline & Goalkeeper & 3.26 & 0.86 to 12.18 & 0.08 \\
\hline & Back & 6.38 & 2.16 to 18.81 & 0.001 \\
\hline \multirow[t]{7}{*}{ Shotst } & Shots attempted (n) & 1.00 & 0.98 to 1.02 & 0.99 \\
\hline & $6 \mathrm{~m}$ shots $(\mathrm{n})$ & 1.00 & 0.96 to 1.04 & 0.86 \\
\hline & Wing shots $(n)$ & 0.93 & 0.86 to 1.00 & 0.04 \\
\hline & $9 m$ shots $(n)$ & 1.02 & 0.99 to 1.04 & 0.22 \\
\hline & $7 m$ shots $(n)$ & 1.00 & 0.94 to 1.07 & 0.92 \\
\hline & Fast-breaks shots (n) & 0.98 & 0.90 to 1.07 & 0.63 \\
\hline & Breakthrough shots (n) & 1.00 & 0.86 to 1.15 & 0.98 \\
\hline \multirow[t]{2}{*}{ Offensive $\ddagger$} & Assists (n) & 1.03 & 0.99 to 1.06 & 0.14 \\
\hline & Turn overs (n) & 1.04 & 0.98 to 1.10 & 0.23 \\
\hline \multirow[t]{2}{*}{ Defensiveł } & Steals (n) & 1.00 & 0.87 to 1.15 & 0.98 \\
\hline & Blocked shots (n) & 0.97 & 0.81 to 1.14 & 0.70 \\
\hline \multirow[t]{3}{*}{$2 \mathrm{~min}$ suspensions } & None & 1 & & \\
\hline & One to two times & 2.50 & 1.14 to 5.28 & 0.02 \\
\hline & Three or more times & 2.14 & 0.91 to 5.01 & 0.07 \\
\hline \multirow[t]{2}{*}{ Red cards } & No & 1 & & \\
\hline & Yes & 0.16 & 0.02 to 1.17 & 0.07 \\
\hline \multirow[t]{2}{*}{ Yellow card } & No & 1 & & \\
\hline & Yes & 1.09 & 0.89 to 1.33 & 0.59 \\
\hline
\end{tabular}

Candidate variables included in the multiple analysis are in bold.

tOR based on one shot increase.

¥OR based on one action (offence or defence) increase.

different ages participating in the tournament. Such a finding, however, highlights the need to compare different age groups of senior players competing in the same event.

\section{Player position}

In the present study, player position was associated with injury risk. More precisely, back players were at approximately seven times greater risk of injury compared with wing players. In agreement with a previous study, back players in a female European handball team had an injury incidence of 54.8 injuries per 1000 hours, which was 2.3 times higher than wing players, who had the lowest incidence (23.6 injuries per 1000 hours) of the

\begin{tabular}{|c|c|c|c|c|}
\hline \multirow[b]{2}{*}{ Risk factors } & & \multicolumn{3}{|c|}{ Multiple regression } \\
\hline & & OR & $95 \% \mathrm{Cl}$ & $P$ values \\
\hline Age (years) & & 1.1 & 1.02 to 1.18 & 0.017 \\
\hline \multirow[t]{4}{*}{ Player positions } & Wing & 1.00 & & \\
\hline & Line & 2.78 & 0.72 to 10.68 & 0.137 \\
\hline & Goalkeeper & 5.03 & 1.15 to 21.94 & 0.031 \\
\hline & Back & 6.79 & 2.25 to 20.54 & 0.001 \\
\hline \multirow[t]{3}{*}{2 min suspensions } & None & 1.00 & & \\
\hline & One to two times & 2.77 & 1.27 to 6.04 & 0.011 \\
\hline & $\begin{array}{l}\text { Three or more } \\
\text { times }\end{array}$ & 2.66 & 1.18 to 6.38 & 0.029 \\
\hline
\end{tabular}

various playing positions. ${ }^{9}$ Moreover, a recent study showed that the majority of injuries occurred during attacking, with back players being the most vulnerable.

Not all studies agree on susceptibility to injury by position, however, as in the present study wing players had the lowest injury rate (19.9 injuries per 1000 hours), while in another study ${ }^{18}$ wings had a higher injury incidence than goalkeepers and backs (93.0 to 53.9 and 88.0 injuries per 1000 hours, respectively) and Giroto $e t \mathrm{al}^{8}$ reported that male goalkeepers had a lower incidence of injuries compared with other playing positions.

The low injury risk of wing players may be explained by the fact that wing players perform significantly more wing shots and fast breaks, and are consequently less exposed to physical confrontations compared with back players (table 3$),{ }^{12}$ as handball rules are very strict relating to wing shots and require that the referees penalise any foul on a player shooting from the wing with a $7 \mathrm{~m}$ throw and/or a $2 \mathrm{~min}$ suspension. ${ }^{27}$

\section{Technical actions}

Interestingly, in the present study, the number of assists was significantly greater for back players compared with wing players. This is an important consideration, as the univariate analysis indicated that the number of assists, which is a typical offensive action, may be a potential risk factor of injury (table 5). This finding is consistent with previous studies showing that more injuries occur while attacking than defending in the central positions of the field, ${ }^{128} 29$ meaning that players who participate more actively in goal-scoring attempts are at greater risk. ${ }^{18}$ In addition, based on systematic video analysis of injuries occurring 
during the 2015 Handball World Championship, Andersson et $a l^{29}$ observed that the match referees were too lenient in their rule interpretation and suggested that stricter application of the rules (and potentially modifying some rules) could reduce the risk of acute match injuries, especially when an attacker performing a jump shot is tackled.

\section{Player suspensions}

The regression model (table 6) also highlights that there was an association between $2 \mathrm{~min}$ suspension and injury rate. Usually, these types of suspensions are given to more aggressive players who are more likely to come into physical contact with opponents and thus receive most often 2 min suspension. ${ }^{27}$ Nevertheless, the results of the present study showed that the risk was almost the same regardless of whether the player had one 2 min suspension or more than three. Indeed, during a tournament with six to nine matches, if a player receives only one 2 min suspension, that could be due to lots of different reasons other than the player's playing style (eg, a certain opponent, a certain referee or just bad luck). However, if a player receives three to four suspensions, then probably that is not just because of the reasons mentioned above, but more likely due to the playing style (ie, playing more aggressive). Therefore, the association between 2 min suspensions and injury is not necessary due to playing style. It could also be explained by the fact that the majority of injuries to defenders occur when they come into contact with the knee/throwing arm (elbow/hand) of an attacker performing a shot with also some of the injuries caused by the ball hitting the defenders. ${ }^{29}$

\section{Methodological considerations}

We acknowledge that the current study was exploratory, not hypothesis-driven and a large number of candidate risk factor variables were explored in the univariate analyses. Therefore, whether there is a causal relationship between player characteristics, the technical components of the game and the risk of match injuries must be interpreted with caution.

The IOC injury and illness surveillance protocol was successfully implemented during the event with a response rate of $94.0 \%$, which is similar to the response rate $(96.7 \%)$ of the 24th Men's Handball World Championship 2015 in Qatar. One challenge was that the Handball World Championship in France was played in several different cities, in contrast to the Handball World Championship in Qatar, where all matches were played in one city. As we did not include technical data from matches with missing injury data in the analyses, these are unlikely to bias the outcome of the study. However, it is difficult to ensure whether all medical teams followed the same reporting standard, so differences in how the definitions of injury and their respective categories and codes were interpreted, may have influenced the results.

The exposure data were not obtained directly by the authors, but were extracted from the IHF website. As per IHF procedures, exposure was measured to the nearest second, which implies that the measurement standards used by tournament staff were rigorous.

Murphy et $a l^{30}$ pointed out that one of the most important limitations in risk factor studies is the relatively small number of subjects and injuries included. In fact, in order to detect 'moderate' to 'strong' associations, 20-50 injury cases are needed, whereas 'small'-to-'moderate' associations would need about 200 injured subjects. ${ }^{31}$ The present study, which included 49 injured players out of the 387 players included, was therefore only powered to detect strong and moderate associations. ${ }^{31}$
Logically, contact injuries are more susceptible to be related to playing style than non-contact ones. However, players who are most involved in the game (by performing more actions including shooting), are also more exposed to overuse injuries. In this context, due to the relatively limited number of match injuries, we included both contact and non-contact injuries in the data set in order not to lose statistical power. Further studies with a larger sample size are needed to analyse contact and overuse injuries separately.

\section{Practical implications and conclusions}

Previous studies, in other sports ${ }^{32} 33$ as well as in handball ${ }^{29}$ have suggested that stricter rule enforcement should be seriously considered in order to reduce the rate of injuries; however, we do not know how realistic it is for players to modify their playing style. Indeed, reducing aggressive play could result in an impaired performance. Even though the IHF already advises referees to heavily sanction fouls on goal-scoring attempts by wing players, it seems that more strict sanctions could also be considered for the back positions. Further research could explore whether changing strategies/tactics to perform more attacks from the wing leads to a reduction in injures, and what effect this has on team performance.

Acknowledgements The authors would like to thank the IHF senior management, all team medical staff members and local organising committee physicians, Dr Frédérique Barthelemy (Nantes), Dr Philippe Paulin (Metz Et Lille), Dr Michel Ducasse (Paris), Dr Françoise Duquesne (Brest), Dr Cindy Conort (Montpellier), Dr Gilles Zmuda (Rouen) and Dr Bertrand Alexis (Albertville), for their outstanding cooperation and contribution to the injury surveillance project throughout the entire 2017 World Championship. The authors would like to thank Mrs Rima Tabanji for her help in the data extraction and transposition and Dr Stephen Targett for his help with English editing. The authors would also like to thank two anonymous reviewers and the associate editor for their suggestions and comments, which improved this manuscript.

Contributors All authors contributed to the study design and data recording preparation. MT, GJ, FA, PL, NP and KC were responsible for the data collection and data analysis. MT, KC and RB interpreted the data and wrote the first draft of the paper. All authors contributed to the final paper. MT and NP are responsible for the overall content as guarantors.

Funding This research received no specific grant from any funding agency in the public, commercial or not-for-profit sectors.

Competing interests None declared.

Patient consent Not required.

Ethics approval The study has been reviewed and approved by the Anti-Doping Lab Qatar (ADLQ), Doha, Qatar.

Provenance and peer review Not commissioned; externally peer reviewed.

\section{REFERENCES}

1 Moller M, Attermann J, Myklebust G, et al. Injury risk in Danish youth and senior elite handball using a new SMS text messages approach. Br J Sports Med 2012;46:531-7.

2 Nielsen $A B, Y$ de J. An epidemiologic and traumatologic study of injuries in handball. Int J Sports Med 1988;9:341-4.

3 Engebretsen L, Soligard T, Steffen $\mathrm{K}$, et al. Sports injuries and illnesses during the London Summer Olympic Games 2012. Br J Sports Med 2013;47:407-14.

4 Junge $A$, Engebretsen L, Mountjoy ML, et al. Sports injuries during the Summer Olympic Games 2008. Am J Sports Med 2009;37:2165-72.

5 Junge $A$, Langevoort $G$, Pipe $A$, et al. Injuries in team sport tournaments during the 2004 Olympic Games. Am J Sports Med 2006;34:565-76.

6 Soligard T, Steffen K, Palmer D, et al. Sports injury and illness incidence in the Rio de Janeiro 2016 Olympic Summer Games: A prospective study of 11274 athletes from 207 countries. Br J Sports Med 2017;51:1265-71.

7 Bahr R, Krosshaug T. Understanding injury mechanisms: a key component of preventing injuries in sport. Br J Sports Med 2005;39:324-9.

8 Giroto N, Hespanhol Junior LC, Gomes MR, et al. Incidence and risk factors of injuries in Brazilian elite handball players: A prospective cohort study. Scand J Med Sci Sports 2017;27:195-202.

9 Wedderkopp N, Kaltoft M, Lundgaard B, et al. Injuries in young female players in European team handball. Scand J Med Sci Sports 1997;7:342-7. 
10 Hopkins WG, Marshall SW, Quarrie KL, et al. Risk factors and risk statistics for sports injuries. Clin J Sport Med 2007;17:208-10.

11 Hassan A, Schrapf N, Ramadan W, et al. Evaluation of tactical training in team handball by means of artificial neural networks. J Sports Sci 2017:35:642-7.

12 Michalsik LB, Aagaard P, Madsen K. Technical activity profile and influence of body anthropometry on playing performance in female elite team handball. J Strength Cond Res 2015;29:1126-38.

13 Tabben $\mathrm{M}$, Coquart J, Chaabène $\mathrm{H}_{\text {, et }}$ al. Time-motion, tactical and technical analysis in top-level karatekas according to gender, match outcome and weight categories. J Sports Sci 2015;33:841-9.

14 van Mechelen W, Hlobil H, Kemper HC. Incidence, severity, aetiology and prevention of sports injuries. A review of concepts. Sports Med 1992;14:82-99.

15 Bahr R. Why screening tests to predict injury do not work-and probably never will.... a critical review. Br J Sports Med 2016;50:776-80.

16 Engebretsen L, Steffen K, Alonso JM, et al. Sports injuries and illnesses during the Winter Olympic Games 2010. Br J Sports Med 2010;44:772-80.

17 Junge $A$, Engebretsen L, Alonso JM, et al. Injury surveillance in multi-sport events: the International Olympic Committee approach. Br J Sports Med 2008;42:413-21.

18 Bere T, Alonso JM, Wangensteen A, et al. Injury and illness surveillance during the 24th Men's Handball World Championship 2015 in Qatar. Br J Sports Med 2015;49:1151-6.

19 International Handball Federation, 2017. Men's World Championships - Fixtures and Results. http://www.ihf.info/en-us/ihfcompetitions/worldchampionships/mensworl dchampionships/menshandballworldchampionshipfrance2017/fixturesandresults. aspxMarch

20 Orchard J, Seward H, Report I. Australian Football League. Sport Health 2009;2010:10-19.

21 Woods C, Hawkins RD, Maltby S, et al. The Football Association Medical Research Programme: an audit of injuries in professional football--analysis of hamstring injuries. Br J Sports Med 2004;38:36-41.
22 Henderson G, Barnes CA, Portas MD. Factors associated with increased propensity for hamstring injury in English Premier League soccer players. J Sci Med Sport 2010;13:397-402.

23 Myer GD, Sugimoto D, Thomas $S$, et al. The influence of age on the effectiveness of neuromuscular training to reduce anterior cruciate ligament injury in female athletes: a meta-analysis. Am J Sports Med 2013;41:203-15.

24 Woollings KY, McKay CD, Emery CA. Risk factors for injury in sport climbing and bouldering: a systematic review of the literature. Br J Sports Med 2015:49:1094-9.

25 Ryan J, DeBurca N, Mc Creesh K. Risk factors for groin/hip injuries in field-based sports: a systematic review. Br J Sports Med 2014;48:1089-96.

26 Niyonsenga JD, Phillips JS. Factors associated with injuries among first-division Rwandan female soccer players. Afr Health Sci 2013;13:1021-6.

27 International Handball Federation, 2010. Changes to the IHF Rules of the Game. http://www.ihf.info/files/Uploads/NewsAttachments/0_Overview\%202010_GB.pdf

28 Olsen OE, Myklebust G, Engebretsen L, et al. Injury pattern in youth team handball: a comparison of two prospective registration methods. Scand J Med Sci Sports 2006:16:426-32.

29 Andersson SH, Cardinale M, Whiteley R, et al. Video analysis of acute injuries and referee decisions during the 24th Men's Handball World Championship 2015 in Qatar. Scand J Med Sci Sports 2018;28:1837-46.

30 Murphy DF, Connolly DA, Beynnon BD. Risk factors for lower extremity injury: a review of the literature. Br J Sports Med 2003:37:13-29.

31 Bahr R, Holme I. Risk factors for sports injuries--a methodological approach. Br J Sports Med 2003:37:384-92.

32 Bjørneboe J, Bahr R, Dvorak J, et al. Lower incidence of arm-to-head contact incidents with stricter interpretation of the Laws of the Game in Norwegian male professional football. Br J Sports Med 2013;47:508-14.

33 Orchard JW, Seward H. Decreased incidence of knee posterior cruciate ligament injury in Australian Football League after ruck rule change. Br J Sports Med 2009:43:1026-30. 